\title{
Resuscitative endovascular balloon occlusion of the aorta (REBOA) and endovascular resuscitation and trauma management (EVTM): a paradigm shift regarding hemodynamic instability
}

\author{
Tal Hörer ${ }^{1,2}$
}

Received: 27 June 2018 / Accepted: 10 July 2018

○) Springer-Verlag GmbH Germany, part of Springer Nature 2018

The management of hemodynamically unstable trauma patients has dramatically changed in the last decades. The concept of damage control, permissive hypotension, and usage of tourniquets and many more exciting developments have probably helped save many lives, both in civilian and military environment [1-10]. Also, the concept of using endovascular tools for bleeding control has been developed over the last 20 years, with major advances such as embolization, endografts, and, lately, the use of Resuscitative Endovascular Balloon Occlusion of the Aorta (REBOA) [3-5, 11-14]. These tools are now gathered together into a new concept called endovascular resuscitation and trauma management (EVTM) [15-17] (http://www.jevtm.com). Many trauma and emergency procedures (i.e., aneurysm repair, visceral and pelvic bleeding, and others) are going through major changes as endovascular and hybrid approaches become available. That is, hemostasis can be achieved with minimally invasive methods, and further surgical trauma to stop bleeding can be avoided. Hemostasis can also be obtained using a hybrid approach, where endovascular and open surgery are combined. It might be speculated that not only mortality but also morbidity might be affected by these methods. More importantly, the EVTM concept, and REBOA within it, may help a team with patients in extremes, convert a difficult bleeding scenario into a more controlled one, or just gain some time [15]. As said, the use of these hybrid and endovascular tools is not limited to trauma, but also applies to other types of bleedings, such as vascular emergencies, post-partum hemorrhages ( $\mathrm{PPH})$, and gastrointestinal and iatrogenic or spontaneous bleeders. EVTM might also be

Tal Hörer

Tal.horer@regionorebrolan.se

1 Department of Cardiothoracic and Vascular Surgery, Örebro University Hospital and University, Örebro, Sweden

2 Department of General Surgery, Örebro University Hospital and University, Örebro, Sweden used for other hemodynamic instabilities with the potential use of extracorporeal membrane oxygenation (ECMO) in different medical emergencies as part of emerging endovascular cardio-pulmonary resuscitation (eCPR). It might be suggested that even patients not undergoing CPR but receiving general resuscitation treatment might benefit from the EVTM concept, thus incorporating eCPR into EVTM (EVTM2018 round table symposium debate, http://www. jevtm.com). REBOA as a trauma procedure has attracted attention in recent years due to its potential to contribute to hemodynamic stability in patients in shock due to noncompressible-torso bleeding [18-21]. REBOA has been used for many years within acute endovascular surgery, and is now spreading into the trauma world and into some trauma guidelines [22-26]. The use of REBOA for ruptured aorta aneurysm has been shown, in the last 20 years, to be effective in facilitating aneurysm repair in unstable patients [17, $22,26]$. Trauma REBOA has gained popularity in the last few years and has been used now in several thousand trauma cases worldwide [11, 19, 20, 27-29]. A huge development in the field has been the introduction of REBOA catheters with smaller diameter (sheaths) that has made REBOA use easier, faster, and available to trauma surgeons, and also might be associated with better outcomes [19, 29]. It should be remembered that, although REBOA seems to be a very effective hemodynamic tool, its use has not yet shown a mortality benefit in trauma patients, and clear indications/ contra-indications for use are not yet well established. It has been shown, though, that it can be used as a bridge to definitive surgical or endovascular treatment [24, 27]. Obviously, REBOA, as a bridge, is never a solution in itself, and there is still a lack of high-grade evidence about the correct indications, selections of patients, and ways for it to be used. REBOA is also associated with ischemia-perfusion injuries and multiple organ failure when used for a prolonged period of time, but data are still lacking regarding the time limits of REBOA use. Newer methods, such as partial REBOA 
(pREBOA), intermitted REBOA (iREBOA), and others, might prove to be beneficial in practical use, and hopefully will decrease ischemia-perfusion injuries [30-34]. There is also an ongoing debate on the use, and possible overuse, of REBOA in trauma and other patients, and there is much to learn about the correct use of REBOA and EVTM methods in bleeding patients [34].

There is a very low level of evidence about REBOA's use for other types of hemodynamic instabilities (such as PPH and others), and there is much research to do in this area (EVTM2018 round table symposium debate, http://www. jevtm.com). It must be remembered, though, that REBOA is just one of the tools in EVTM, and there must be a clear plan for its use in definitive bleeding control.

In this issue of the European Journal of Trauma and Emergency Surgery, REBOA is given its place as an evolving technique for bleeding management. Hörer et al. [35] report on their single-center experiences REBOA, and on the lessons learned from endovascular and hybrid ruptured aortic aneurysm treatment that will lead to the development of the EVTM concept. Matsumura et al. [36] report on evidence in the DIRECT-IABO registry on using REBOA for non-hemorrhagic shock. Reva et al. [37] investigate the optimal period for aortic balloon occlusion in an animal model. Manzano-Nunez et al. reviewed the literature on the use of REBOA for bleeding control in patients with adherent placenta [38] and the relevance of hypotension [39]. Finally Dongen et al. [40] provide a review on the use of REBOA in major exsanguination.

Funding No Funding received for this work.

\section{Compliance with ethical standards}

Conflict of interest The author declares no conflict of interest

Ethical standards Non-relevant. The author declares compliance with ethical standards.

Informed consent Not needed.

\section{References}

1. Blackbourne LH, Baer DG, Eastridge BJ, Kheirabadi B, Bagley S, Kragh JF Jr, et al. Military medical revolution: prehospital combat casualty care. J Trauma Acute Care Surg. 2012;73(6 Suppl 5):372-7.

2. Biffl WL, Smith WR, Moore EE, Gonzalez RJ, Morgan SJ, Hennessey T, et al. Evolution of a multidisciplinary clinical pathway for the management of unstable patients with pelvic fractures. Ann Surg. 2001;233(6):843-50.

3. Stannard A, Morrison JJ, Scott DJ, Ivatury RA, Ross JD, Rasmussen TE. The epidemiology of noncompressible torso hemorrhage in the wars in Iraq and Afghanistan. J Trauma Acute Care Surg. 2013;74(3):830-4.
4. Faulconer ER, Branco BC, Loja MN, Grayson K, Sampson J, Fabian TC, et al. Use of open and endovascular surgical techniques to manage vascular injuries in the trauma setting: a review of the American Association for the Surgery of Trauma PROspective Observational Vascular Injury Trial registry. J Trauma Acute Care Surg. 2018;84(3):411-7.

5. Branco BC, DuBose JJ, Zhan LX, Hughes JD, Goshima KR, Rhee $\mathrm{P}$, et al. Trends and outcomes of endovascular therapy in the management of civilian vascular injuries. J Vasc Surg. 2014;60(5):1297-307. (307 e1).

6. Northern DM, Manley JD, Lyon R, Farber D, Mitchell BJ, Filak $\mathrm{KJ}$, et al. Recent advances in austere combat surgery: use of aortic balloon occlusion as well as blood challenges by special operations medical forces in recent combat operations. J Trauma Acute Care Surg. 2018;85(1S Suppl 2):S98-103.

7. Fox CJ, Gillespie DL, O’Donnell SD, Rasmussen TE, Goff JM, Johnson CA, et al. Contemporary management of wartime vascular trauma. J Vasc Surg. 2005;41(4):638-44.

8. Morrison JJ, Rasmussen TE. Noncompressible torso hemorrhage: a review with contemporary definitions and management strategies. Surg Clin N Am. 2012;92(4):843-58 (vii).

9. Morrison JJ. Noncompressible torso hemorrhage. Crit Care Clin. 2017;33(1):37-54.

10. Dubose JJ, Azizzadeh A, Estrera AL, Safi HJ. Contemporary management of blunt aortic trauma. J Cardiovasc Surg. 2015;56(5):751-62.

11. DuBose JJ. The AAST AORTA registry and data on REBOA. J Trauma Acute Care Surg. 2016;81(3):409-19.

12. Hoffer EK. Endovascular intervention in thoracic arterial trauma. Injury. 2008;39(11):1257-74.

13. Pang D, Hildebrand D, Bachoo P. Thoracic endovascular repair (TEVAR) versus open surgery for blunt traumatic thoracic aortic injury. Cochrane Database Syst Rev. 2015;9:CD006642.

14. Spahn DR, Bouillon B, Cerny V, Coats TJ, Duranteau J, Fernandez-Mondejar E, et al. Management of bleeding and coagulopathy following major trauma: an updated European guideline. Crit Care. 2013;17(2):R76.

15. Hörer TM, Skoog P, Pirouzram A, Nilsson KF, Larzon T. A small case series of aortic balloon occlusion in trauma: lessons learned from its use in ruptured abdominal aortic aneurysms and a brief review. Eur J Trauma Emerg Surg. 2016;42(5):585-92.

16. Hörer T. Paradigm shift in management of trauma and life-threatening bleeding. Lakartidningen. 2016;113:ECZ9.

17. Hörer TM, Hebron D, Swaid F, Korin A, Galili O, Alfici R, et al. Aorta balloon occlusion in trauma: three cases demonstrating multidisciplinary approach already on patient's arrival to the emergency room. Cardiovasc Interv Radiol. 2016;39(2):284-9.

18. Morrison JJ, Galgon RE, Jansen JO, Cannon JW, Rasmussen TE, Eliason JL. A systematic review of the use of resuscitative endovascular balloon occlusion of the aorta in the management of hemorrhagic shock. J Trauma Acute Care Surg. 2016;80(2):324-34.

19. Sadeghi M, Nilsson KF, Larzon T, Pirouzram A, Toivola A, Skoog $\mathrm{P}$, et al. The use of aortic balloon occlusion in traumatic shock: first report from the ABO trauma registry. Eur J Trauma Emerg Surg. 2017. https://doi.org/10.1007/s00068-017-0813-7.

20. DuBose JJ, Group AS. RE: the AAST AORTA registry and data on REBOA. J Trauma Acute Care Surg. 2016;81(3):617-8.

21. Saito N, Matsumoto H, Yagi T, Hara Y, Hayashida K, Motomura $\mathrm{T}$, et al. Evaluation of the safety and feasibility of resuscitative endovascular balloon occlusion of the aorta. J Trauma Acute Care Surg. 2015;78(5):897-903. (discussion 4).

22. Malina M, Veith F, Ivancev K, Sonesson B. Balloon occlusion of the aorta during endovascular repair of ruptured abdominal aortic aneurysm. J Endovasc Ther. 2005;12(5):556-9.

23. Borger van der Burg BLS, van Dongen T, Morrison JJ, Hedeman Joosten PPA, DuBose JJ, Hörer TM, et al. A systematic review 
and meta-analysis of the use of resuscitative endovascular balloon occlusion of the aorta in the management of major exsanguination. Eur J Trauma Emerg Surg. 2018. https://doi.org/10.1007/ s00068-018-0959-y.

24. Brenner ML, Moore LJ, DuBose JJ, Tyson GH, McNutt MK, Albarado RP, et al. A clinical series of resuscitative endovascular balloon occlusion of the aorta for hemorrhage control and resuscitation. J Trauma Acute Care Surg. 2013;75(3):506-11.

25. Coccolini F, Stahel PF, Montori G, Biffl W, Horer TM, Catena F, et al. Pelvic trauma: WSES classification and guidelines. World J Emerg Surg. 2017;12:5.

26. Mayer D, Aeschbacher S, Pfammatter T, Veith FJ, Norgren $\mathrm{L}$, Magnuson A, et al. Complete replacement of open repair for ruptured abdominal aortic aneurysms by endovascular aneurysm repair: a two-center 14-year experience. Ann Surg. 2012;256(5):688-96.

27. DuBose JJ, Scalea TM, Brenner M, Skiada D, Inaba K, Cannon J, et al. The AAST prospective Aortic Occlusion for Resuscitation in Trauma and Acute Care Surgery (AORTA) registry: data on contemporary utilization and outcomes of aortic occlusion and resuscitative balloon occlusion of the aorta (REBOA). J Trauma Acute Care Surg. 2016;81(3):409-19.

28. Matsumura Y, Matsumoto J, Kondo H, Idoguchi K, Funabiki T, Investigators D-I. Partial occlusion, conversion from thoracotomy, undelayed but shorter occlusion: resuscitative endovascular balloon occlusion of the aorta strategy in Japan. Eur J Emerg Med. 2017. https://doi.org/10.1097/MEJ.0000000000000466.

29. Matsumura Y, Matsumoto J, Kondo H, Idoguchi K, Ishida T, Kon $\mathrm{Y}$, et al. Fewer REBOA complications with smaller devices and partial occlusion: evidence from a multicentre registry in Japan. Emerg Med J EMJ. 2017;34(12):793-9.

30. Davidson AJ, Russo RM, Reva VA, Brenner ML, Moore LJ, Ball $\mathrm{C}$, et al. The pitfalls of resuscitative endovascular balloon occlusion of the aorta: risk factors and mitigation strategies. J Trauma Acute Care Surg. 2018;84(1):192-202.

31. Davidson AJ, Russo RM, DuBose JJ, Roberts J, Jurkovich GJ, Galante JM. Potential benefit of early operative utilization of low profile, partial resuscitative endovascular balloon occlusion of the aorta (P-REBOA) in major traumatic hemorrhage. Trauma Surg Acute Care Open. 2016;1(1):e000028.

32. Hörer TM, Cajander P, Jans A, Nilsson KF. A case of partial aortic balloon occlusion in an unstable multi-trauma patient. Trauma Engl. 2016;18(2):150-4.

33. Williams TK, Johnson A, Neff L, Hörer TM, Moore L, Brenner $\mathrm{M}$, et al. "What's in a name?" A consensus proposal for a common nomenclature in the endovascular resuscitative management and REBOA literature. J Endovasc Resusc Trauma Manag. 2017;1(1):9-12.
34. Hörer TM, Morrison JJ, DuBose JJ, Reva VA, Matsumoto J, Matsumura Y, Falkenberg M, Delle M, Skoog P, Pirouzram A, et al. Top stent manual, 1st edn. Örebro University Hospital. 2017. ISBN 978-91-639-2522-1.

35. Sadeghi M, Nilsson KF, Larzon T, Pirouzram A, Toivola A, Skoog P, Idoguchi K, Kon Y, Ishida T, Matsumara Y, Matsumoto J, Reva V, Maszkowski M, Bersztel A, Caragounis E, Falkenberg M, Handolin L, Kessel B, Hebron D, Coccolini F, Ansaloni L, Madurska MJ, Morrison JJ, Hörer TM (2017) The use of aortic balloon occlusion in traumatic shock: first report from the ABO trauma registry. Eur J Trauma Emerg Surg. https://doi.org/10.1007/s0006 8-017-0813-7

36. Matsumura Y, Matsumoto J, Idoguchi K, Kondo H, Ishida T, Kon Y, Tomita K, Ishida K, Hirose T, Umakoshi K, Funabiki T, DIRECT-IABO investigators (2017) Non-traumatic hemorrhage is controlled with REBOA in acute phase then mortality increases gradually by non-hemorrhagic causes: DIRECT-IABO registry in Japan. Eur J Trauma Emerg Surg. https://doi.org/10.1007/s0006 8-017-0829-z

37. Reva VA, Matsumura Y, Hörer T, Sveklov DA, Denisov AV, Telickiy SY, Seleznev AB, Bozhedomova ER, Matsumoto J, Samokhvalov IM, Morrison JJ (2016) Resuscitative endovascular balloon occlusion of the aorta: what is the optimum occlusion time in an ovine model of hemorrhagic shock? Eur J Trauma Emerg Surg. https://doi.org/10.1007/s00068-016-0732-z

38. Manzano-Nunez R, Escobar-Vidarte MF, Naranjo MP, Rodriguez F, Ferrada P, Casallas JD, Ordoñez CA (2017) Expanding the field of acute care surgery: a systematic review of the use of resuscitative endovascular balloon occlusion of the aorta (REBOA) in cases of morbidly adherent placenta. Eur J Trauma Emerg Surg. https://doi.org/10.1007/s00068-017-0840-4

39. Manzano-Nunez R, Herrera-Escobar JP, DuBose J, Hörer T, Galvagno S, Orlas CP, Parra MW, Coccolini F, Sartelli M, FallaMartinez JC, García AF, Chica J, Naranjo MP, Sanchez AI, Salazar CJ, Calderón-Tapia LE, Lopez-Castilla V, Ferrada P, Moore EE, Ordonez CA (2018) Could resuscitative endovascular balloon occlusion of the aorta improve survival among severely injured patients with post-intubation hypotension? Eur J Trauma Emerg Surg. https://doi.org/10.1007/s00068-018-0947-2

40. Borger van der Burg BLS, van Dongen TTCF, Morrison JJ, Hedeman Joosten PPA, DuBose JJ, Hörer TM, Hoencamp R (2018) A systematic review and meta-analysis of the use of resuscitative endovascular balloon occlusion of the aorta in the management of major exsanguination. Eur J Trauma Emerg Surg. https://doi. org/10.1007/s00068-018-0959-y 